\title{
Mekansal Karar Destek Sistemleri ile Arazi için Genel Sınır Haritasının Oluşturulması
}

\author{
Hüseyin Hakl1 \\ Bilgisayar Mühendisliği Bölümü, Mühendislik-Mimarlık Fakültesi, Necmettin Erbakan Üniversitesi, Konya, Türkiye
}

\section{$\ddot{O} z$}

İnsan beyninin bilgi saklama ve işleme ile ilgili kapasitesinin sınırlı olması nedeniyle karar verme esnasında hata yapma olasılığı yüksek olmakta ve problem çözme süreci zaman almaktadır. Bu nedenle, problemin tanımlanması, hızlı bir şekilde çözülmesi ve destek sağlanması işlemlerinde karar vericilere yardımcı olan bilgisayar temelli karar destek sistemleri birçok alanda kullanılmaktadır. Arazi yönetimi için kullanılan en önemli araçlardan biri olan arazi toplulaştırmanın yapılabilmesi için araziye ait genel sınır haritasının oluşturulması işlemi zaman alıcı ve hata yapma olasılığı yüksek bir problemdir. $\mathrm{Bu}$ çalışmada, genel sınır haritasının oluşturulması esnasında, karar vericiye destek sağlaması, hata ihtimalini ortadan kaldırması ve hızlı bir şekilde süreci tamamlaması için basit bir mekansal karar destek sistemi önerilmiştir. Önerilen sistem gerçek bir arazi üzerinde test edilmiş ve birkaç dakika içinde hatasız olarak araziye ait genel sınır haritası elde edilmiştir.

Anahtar kelimeler: Mekansal karar destek sistemleri, coğrafi bilgi sistemi, genel sınır haritası

\section{Generating a General Boundary Map for Land with Spatial Decision Support Systems}

\author{
Huseyin Hakli \\ Department of Computer Engineering, Faculty of Engineering and Architecture, Necmettin Erbakan University,
} Konya, Turkey

\begin{abstract}
Due to the fact that the capacity of the human brain to store and process information is limited, it is highly probable to make mistakes during decision making and the problem-solving process is time consuming. Therefore, computer-based decision support systems which help decision makers to identify, quickly resolve, and support their problem are used in many areas. Generation of the general boundary map of the land for the land consolidation, which is one of the most important tool used for land management, is a time consuming and error-prone problem. In this study, a simple spatial decision support system has been proposed during the generation of the general border map, to provide decision support, to remove the possibility of error, and to quickly complete the process. The proposed system was tested on a real land and within a few minutes a generic boundary map of the land was obtained without error.
\end{abstract}

Key words: Spatial decision support systems, geographic information system, general boundary map

*Corresponding author: Address: Faculty of Engineering and Architecture, Department of Computer Engineering, Necmettin Erbakan University, 42140, Konya TURKEY. E-mail address: hhakli@konya.edu.tr, Phone: $+903323252024$ 


\section{Giriş}

Karmaşık ve veri miktarı büyük problemler karşısında hata oranları azaltmak ve verilen kararların doğruluğunu arttırmak için hızlı bir şekilde gelişen bilgisayar teknolojisinden yararlanmak kaçınılmazdır. Bu noktada, bilgileri düzenleme, kararları modelleme, bilgilerin analizini gerçekleştirme ve belirli modeller kullanarak karar vericilere destek sağlama görevlerini gerçekleştiren bilgisayar temelli sistemlere karar destek sistemleri (KDS) denilmektedir [1]. Problemin farkına varılması, tanımlanması, problem karşısında karar alınırken destek sağlanması ve problemin çözülmesi esnasında tüm verilerin gözden geçirilebilmesi ve test edilebilmesi konularında karar destek sistemleri rol almaktadır [2].

İnsan beyninin bilgi saklama ve işleme ile ilgili kapasitesi sınırlı olması nedeniyle karar verme esnasında hata yapması ya da fazla iş yükü sonucunda yanlış tespitlerde bulunması mümkündür [3]. Ayrıca zaman konusundaki kısıtlar karar vericileri basit işlemler de bile hataya sürüklemekte iken bilgisayarların bilgi işleme ve analiz yeteneklerinin daha başarılı ve hızlı olması sayesinde zaman sıkıntısının etkisi KDS ile azaltılabilmektedir [4]. Uygulama alanı çok geniş olan KDS, kanser hücrelerinin tespiti [5], bina güçlendirme [6], tarımda sulama yöntemi [7], ulaşım planlaması [8,9], personel iş yükü dengeleme [10], seri suçların tespiti [11] gibi birçok karmaşık ve gerçek dünya problemlerinin çözümünde kullanılmıştır.

Arazi parçalanmasının çözümü için en yararlı arazi yönetimi yaklaşımı olan arazi toplulaştırma (AT), birçok karmaşık aşamadan oluşmaktadır [12]. AT sürecinin temel aşamalarını gerçekleştirebilmek için, araziye ait bazı verilerin hazırlanması gerekmektedir. Bu verilerden bir tanesi, AT çalışmalarının gerçekleştirileceği araziye ait genel sınır haritasıdır. Genel sınır haritası ile arazi düzenlemesine girecek ve girmeyecek olan kadastro parselleri tespit edilmekte, düzenleme sınırı da belirlenmektedir. Genel sınır haritası, tekniker tarafından manuel olarak arazi üzerindeki kırık noktalara tek tek tıklanarak hazırlanmakta, bu durumda olası veri ve zaman kayıplarına yol açmaktadır. Bu problemlerin üstesinden gelebilmek için, genel sınır haritasının oluşturulması esnasında karar vericiye kolaylık sağlaması adına basit bir mekansal karar destek sistemi önerilmiştir. Hazırlanan karar destek sistemi gerçek bir arazi üzerine uygulanmış ve test edilmiştir. Sonuçlar, tekniker ile birkaç saat içinde ve hata yapma olasılığı yüksek olarak hazırlanan genel sınır haritasının, önerilen sistem ile hatasız ve sadece birkaç dakika içinde oluşturulduğunu göstermektedir.

Çalışmanın kalan bölümleri şu şekildedir: Bölüm 2, genel sınır problemini ve mekânsal karar destek sistemlerini açıklamaktadır. Önerilen sistem Bölüm 3 'te anlatılmıştır. Sistemin gerçek bir arazi üzerinden uygulaması Bölüm 4'te ve sonuç Bölüm 5 'te sunulmuştur.

\section{Materyal ve Metot}

\subsection{Genel Sınır Haritasının Oluşturulması}

AT sürecinin ilk alt işlemlerinden biri olan genel sınır haritasının hazırlanması ile araziye ait düzenlemeye girecek parseller ve proje sınırı belirlenmektedir. Genel sınır, araziye ait kadastro parsellerinin dış kenarları üzerindeki kırık noktalar takip edilerek tekniker tarafından Şekil 1'deki 
gibi oluşturulmaktadır. Teknikerin kırık noktaların hepsini tespit ederek genel sınır haritasına eklemesi Şekil 1 (a)’ da gösterilirken, Şekil 1 (b)' de ise araziye ait genel sınır haritası sunulmuştur.

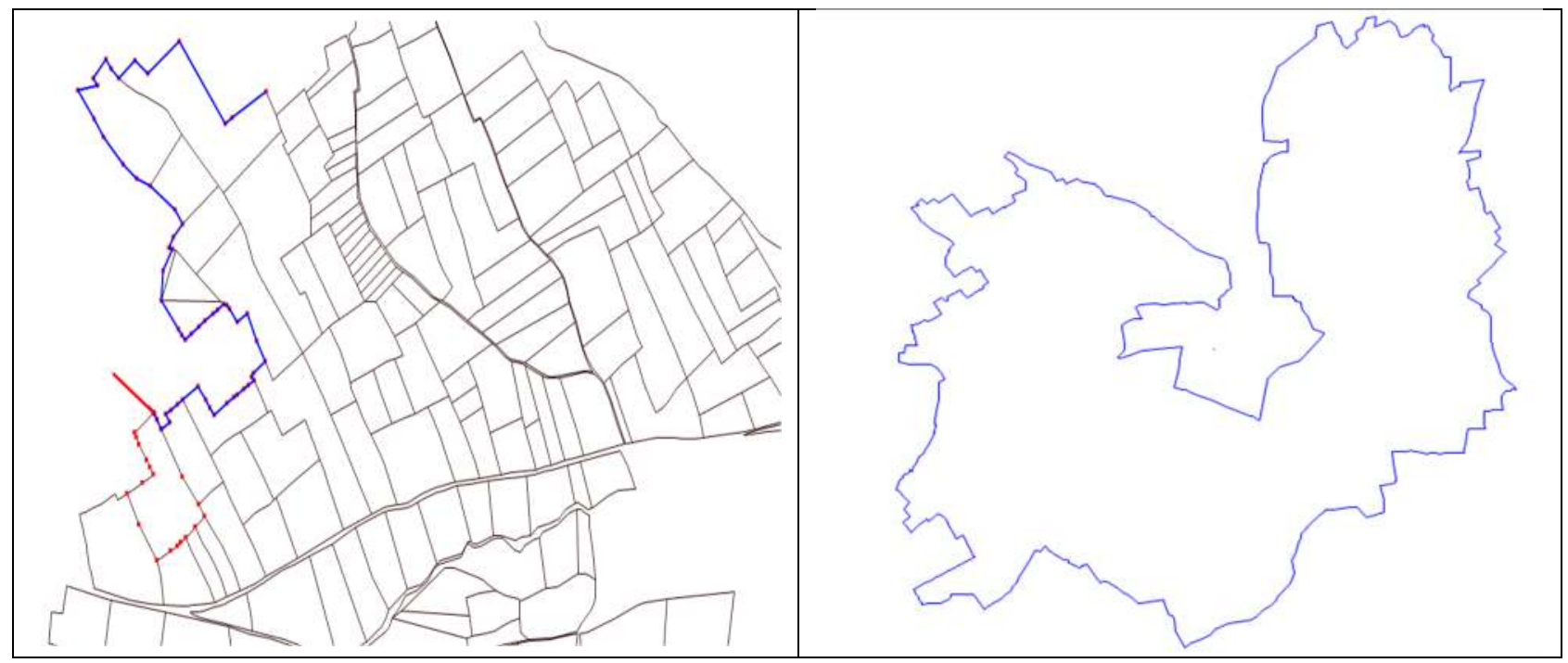

(a)

(b)

Şekil 1. Genel sınır haritasının oluşturulması (a) ve genel sınır haritası (b)

Kırık noktaların biri ya da birkaçının atlanarak/unutularak dikkate alınmaması durumunda genel sınır haritası hatalı bir şekilde çıkarılacaktır. Bu durumda, araziye komşu olan köylerdeki parsellerin düzenlemeye dahil olması ya da mevcut arazideki parsellerin belli bir bölümünün dışarıda kalmasına sebep olacaktır. Yapılan bu hata, sürecin başında tespit edilememesi durumunda kendinden sonra gelen tüm aşamaları da hatalı bir şekilde ilerletecek ve tüm işlemlerin baştan yapılmasını gerektirecektir. Ayrıca bu işlem, arazinin büyüklüğüne göre değişkenlik gösterse de yaklaşık olarak birkaç saat içinde tamamlanabilmektedir. Bu nedenlerle hem hata yapma durumunu sıfıra indirgeyecek hem de çok daha kısa sürede genel sınırın oluşturulmasını sağlayacak bir sisteme ihtiyaç duyulmaktadır.

\subsection{Mekânsal Karar Destek Sistemleri}

Genel sınır haritasının oluşturulması esnasında Şekil 1'de görüldüğü gibi mekânsal veriler kullanılmaktadır. Bu nedenle bir coğrafi bilgi sistemine (CBS) ihtiyaç duyulmaktadır. CBS, teknolojisi, mekânsal verileri düzenlemek ve analiz etmek için bir araç olarak geliştirilmiştir [13]. Bir başka ifade ile CBS, mekânsal ve mekânsal olmayan bilgilerin toplanması, saklanması işlenmesi ve sunulması görevlerini bir bütünlük içerisinde gerçekleştiren bir bilgi sistemidir [14].

Mekânsal karar destek sistemleri (MKDS) ise, bir karar durumunda mekânsal bilgi gerekli bir etken olduğunda CBS'nin, KDS ile birleştirilmesi olarak tanımlanabilir [3, 15]. MKDS, CBS'nin depolama, arama ve geri alma yeteneklerini karar modelleri ile birleştirir ve mekânsal problemlerle ilgili karar vermeyi desteklemek için algoritmaları optimize etmektedir [16]. Her 
ikisi de CBS teknolojisine dayanmasına rağmen MKDS ve CBS aynı değildir. MKDS, belirli bir problem için bir çözüm sunarken, geleneksel GIS çoklu uygulamalar için çalışmak üzere tasarlanmış çok gelişmiş bir teknik araç kutusu sağlar [13].

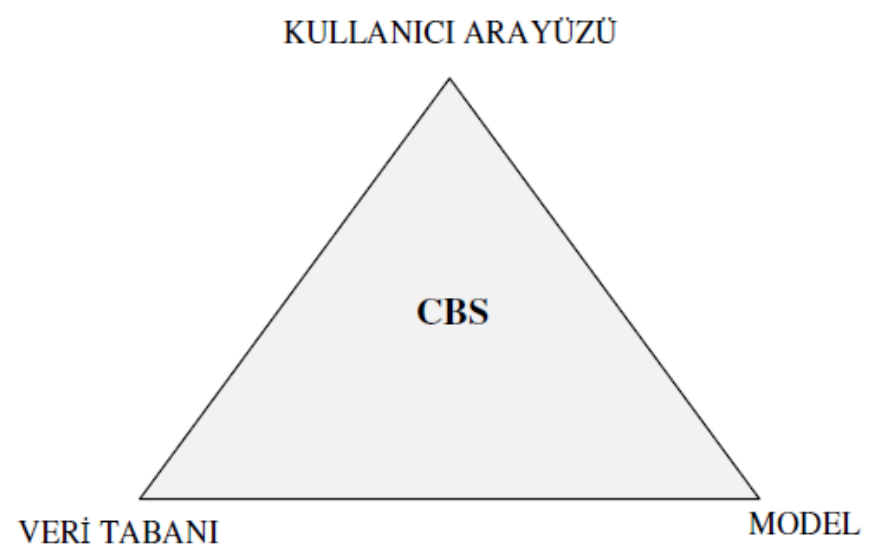

Şekil 2. Bir MKDS’nin bileşenleri [3]

Şekil 2' bir MKDS' ye ait bileşenler gösterilmektedir [3]. CBS sistemini kullanan MKDS, veri tabanı yönetim sistemi, model tabanı yönetim sistemi ve etkileşimli bir kullanıcı arayüzünden oluşmaktadir.

\section{MKDS ile Genel Sınır Haritasının Oluşturulması}

Genel sınır haritasının bir MKDS ile oluşturulmasını sağlamak için bir CBS ortamının hazırlanmasına ve bazı bilgilere ihtiyaç duyulmaktadır. Bu çalışma, 7170197 numaralı Tübitak1507 projesinin alt iş adımlarından birini oluşturmakta ve belirtilen proje kapsamında gerçekleştirilmektedir. Bu nedenle yapılan çalışmada, proje için hazırlanan CBS altyapısı ve veritabanı sistemi kullanılmıştır.

Tekniker için bir kenarın genel sınıra ait olup olmadığını tespit etmek kolaydır fakat bunu bir bilgisayar ile gerçekleştirmek için gerekli algoritma dikkatli bir şekilde hazırlanmalıdır. Bir bilgisayar ise arazi üzerinde tüm kenarları çok kısa bir süre içinde işleyebilirken, tekniker tarafından bu işlemin kısa bir sürede tamamlanması zor olmaktadır. Bu nedenlerle, teknikerin karar verme süreci hızlandıracak ve yapabileceği hataların önüne geçerek işlem doğruluğunu arttıracak bir MKDS tasarlanmış ve akış diyagramı Şekil 3'de verilmiştir.

Bir arazi yollar ve su kanalları nedeniyle birbiri ile bağlantısı olmayan farklı alt alanlara bölünmektedir. Genel sınır haritası hazırlanırken, alt alanlar arasında geçişlerin sağlanabilmesi için tekniker tarafından bu kenarların belirlenmesi gerekmektedir. Tekniker tarafından çizilen bu geçişlerin ilki dikkate alınarak sistem çalışmaya başlamaktadır. Şekil 3'de gösterildiği gibi, geçerli nokta bu çizginin ilk noktasına tekrar dönene kadar önerilen MKDS çalışmaya devam edecektir. Eğer sistem kullanıcı tarafindan çizilen bir nokta üzerinde ise, bu noktaya ait çizgileri genel sınır haritasına dahil eder ve o alt alandaki tüm poligonları belirleyerek diğer noktaya geçer. 


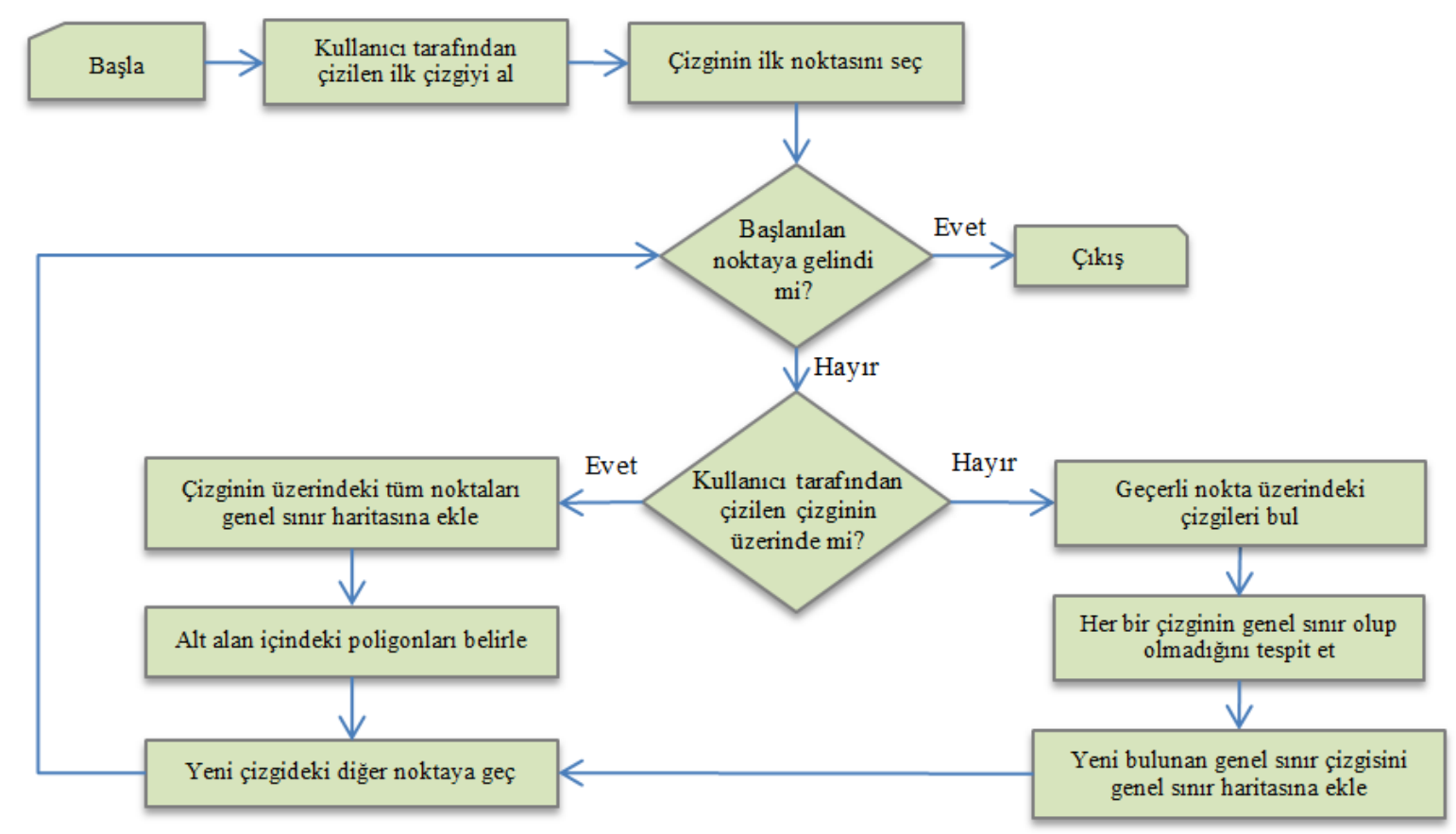

Şekil 3. Genel sınır haritasının oluşturulması için akış diyagramı

Kullanıcı tarafından çizilmeyen bir nokta üzerinde ise bu noktaya ait çizgileri, alt alandaki tüm poligonlar ile karşılaştırır ve birden fazla poligonun bu kenara sahip olduğu durumda herhangi bir işlem gerçekleştirmez. Ama mevcut çizgi sadece bir poligon ait ise bu kenar genel sınır haritasına eklenir ve yeni noktaya geçilir. Şekil 4'de belirtilen işlemler ve ifadeler gösterilmektedir.

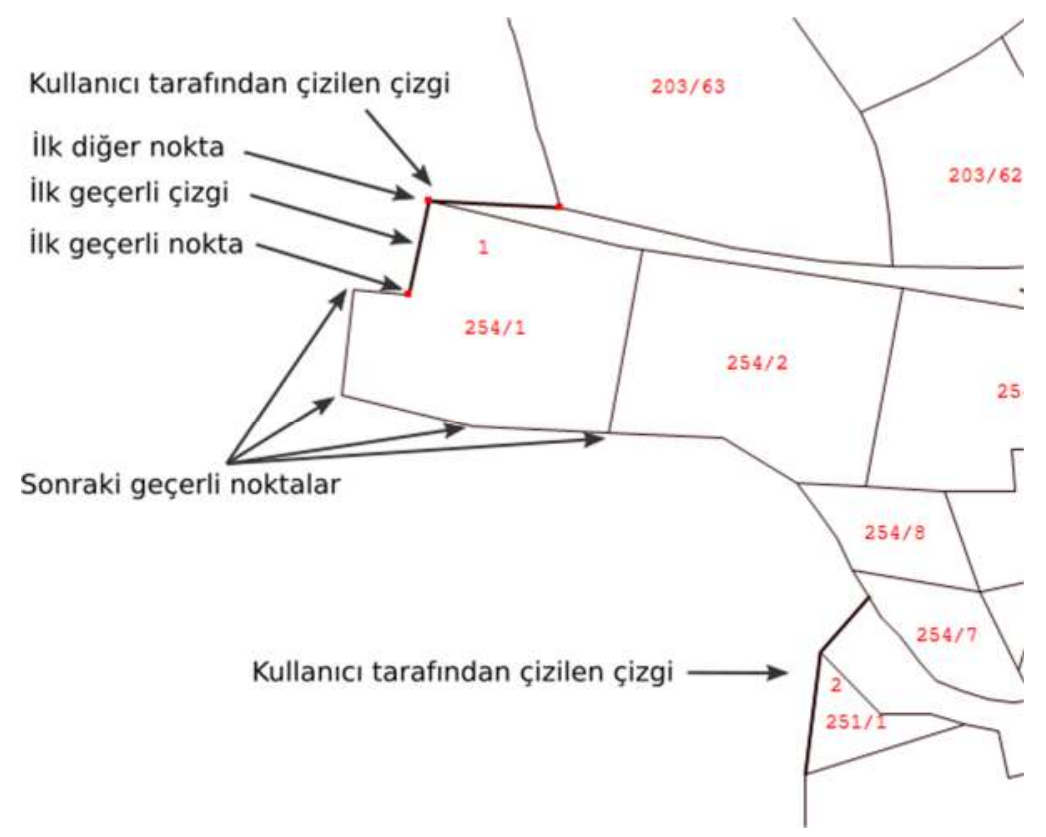

Şekil 4. Genel sınır haritasının oluşturulması işlemi 


\section{4. Önerilen Sistemin Gerçek Proje Sahası Üzerinde Uygulanması}

Önerilen sistemin performansını ve başarısını değerlendirmek için, gerçek bir arazi üzerinde uygulaması gerçekleştirilmiştir. Konya ili Selçuklu ilçesinde bulunan Çaltı köyü çalışma alanı olarak seçilmiştir. Yaklaşık 2411 ha büyüklüğündeki Çaltı köyünde 1310 kadastro parseli bulunmaktadır. Çaltı köyü genel sınır haritası 771 farklı noktadan oluşmaktadır. Önerilen sistemin uygulanabilmesi için ilk olarak yollar ve su kanalları ile bölünmüş arazi üzerindeki geçişlerin tekniker tarafından Şekil 5'te gösterildiği gibi birleştirilmesi gerekmektedir. Şekil 5 (a)'da kırmızı ile gösterilen çizgiler alt alanları birbirine bağlamaktadır. Şekil 5 (b)'de ise bu bölümlerden birinin yakınlaştırılmış hali gösterilmektedir.

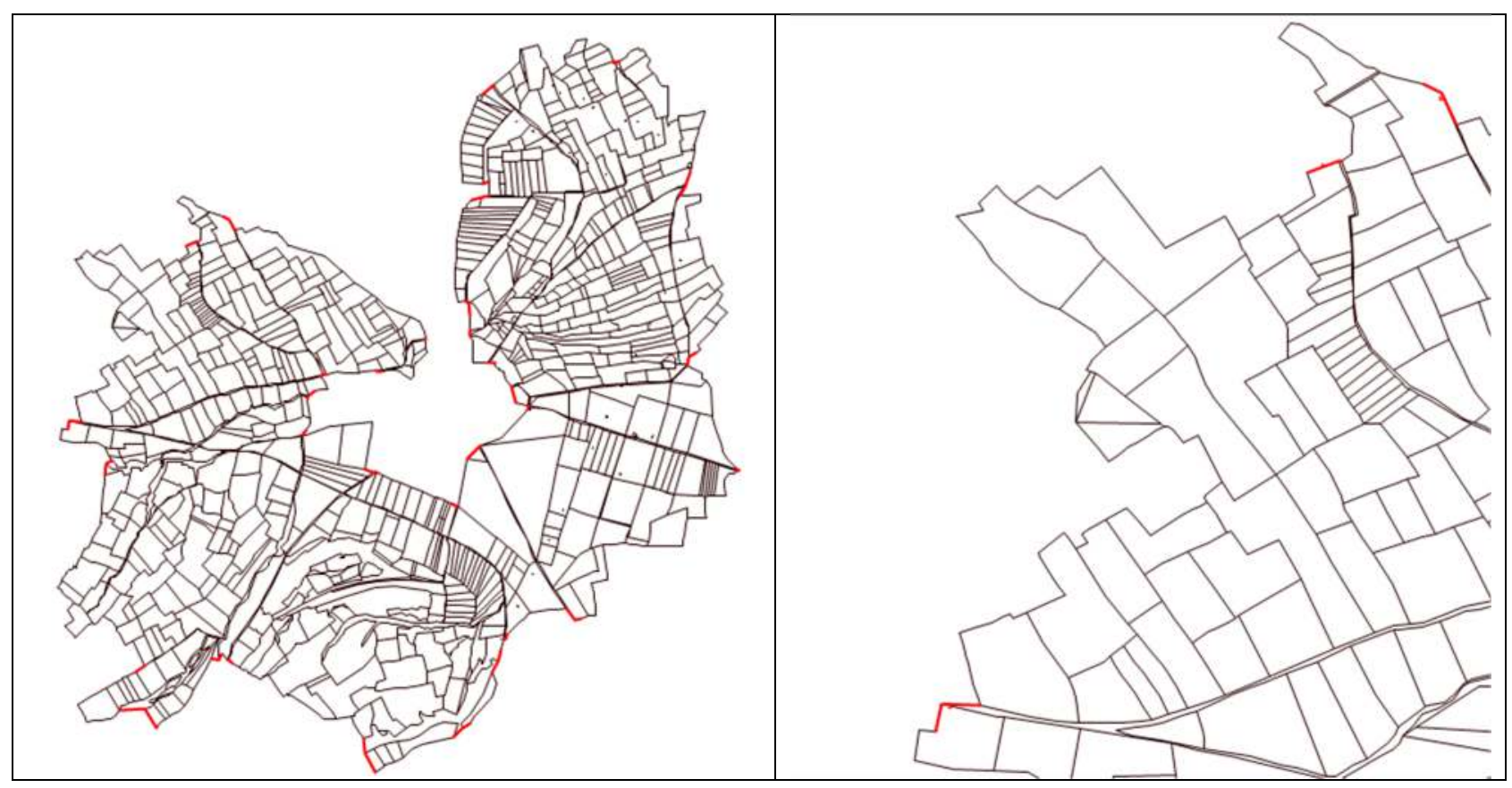

(a)

(b)

Şekil 5. Arazi üzerindeki alt alanların birleştirilmesi (a) ve yakınlaştırılmış görünümü (b)

Bu işlem tamamlandıktan sonra, önerilen sistem ilk çizilen kırmızı çizgiden başlayarak Şekil 3'de verilen karar modeline göre bir çizginin genel sınıra ait olup olmadığına karar verir. Her kırmızı çizgi yeni bir alt alan anlamına geldiği için bu alt alandaki poligonlar belirlenir ve hafizada tutulur. Yeni noktaya geçildiğinde bu noktaya ait çizgiler o alt alandaki poligonların kenarları ile karşılaştırılır. Eğer mevcut kenar sadece tek bir poligona ait ise genel sınır haritasına eklenir ve yeni noktaya geçilir. Başlangıç noktasına tekrar gelene kadar süreç aynı şekilde devam eder. Önerilen sistem Çaltı köyüne uygulanmış ve sadece birkaç dakika içinde genel sınır haritası başarılı bir şekilde oluşturulmuştur. Çaltı köyüne için önerilen sistem ile oluşturulan genel sınır haritası Şekil 6'da verilmektedir. 


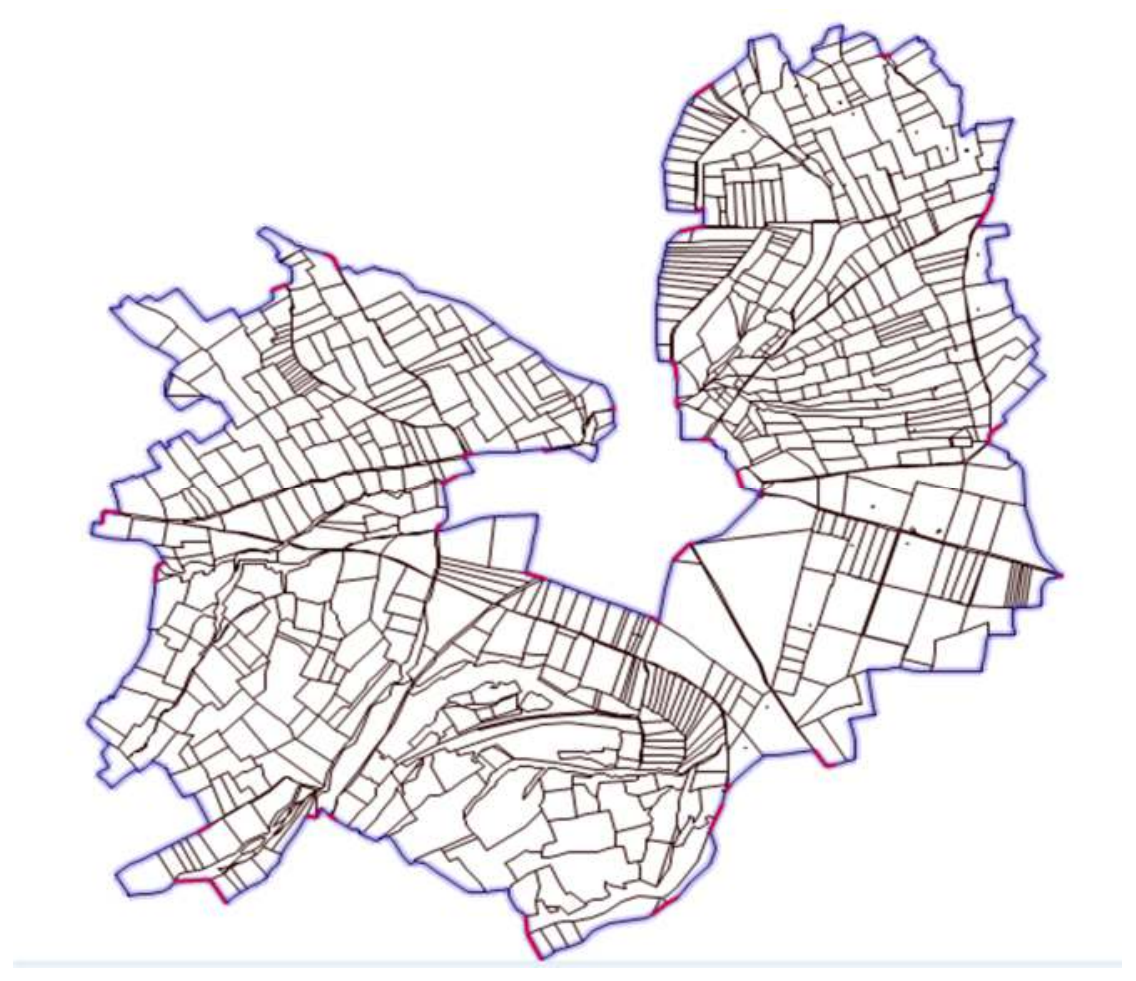

Şekil 6. Önerilen sistem ile oluşturulan genel sınır haritası

\section{Sonuç}

Bu çalışmada, bir araziye ait genel sınır haritasının oluşturulması esnasında, karar vericiye destek sağlanması, problemin hızlı çözülmesi ve hata riskinin ortadan kaldırılması için basit bir mekânsal karar destek sistemi önerilmiştir. Önerilen sistem, Konya ili Çaltı köyüne uygulanarak test edilmiştir. Genel sınır haritası tekniker tarafından normalde 1-2 saat içinde tamamlanabilen ve hata yapma riski yüksek olan bu problem için, 771 noktaya sahip genel sınır haritasının önerilen sistem ile birkaç dakika içinde oluşturulması sağlanmıştır. Böylece süreç hızlandırılmış ve hata yapma riski azaltılmıştır. Daha fazla noktaya sahip arazilerde, önerilen sistemin avantaj1 daha fazla ön plana çıkacaktır. Gelecek çalışmalar için, önerilen sistem farklı araziler üzerinde test edilebilir ve tekniker kontrolünden tamamen çıkarılarak tam otomatik bir çözüm yolu önerilebilir.

\section{Teşekkürler}

Bu çalışma, Türkiye Bilimsel ve Teknolojik Araştırma Kurumu (TÜBİTAK) tarafından 7170197 numaralı proje kapsamında desteklenmiştir. 


\section{Kaynakça}

1. Sauter, V., Decision Support Systems: An Applied Managerial Approach. 1997: John Wiley \& Sons, Inc, USA.

2. Davis, G.B., Management Information Systems. 1974: McGraw-Hill Book Company,Newyork.

3. Uyan, M., Arazi Düzenlemesi Çalışmalarında Mekansal Karar Destek Sistemleri Kurulumu ve Uygulamast, in Harita Mühendisliği Bölümü. 2011, Selçuk Üniversitesi: Fen Bilimleri Enstitüsü.

4. Topcu, Y., Çok ölçütlü sorun çözümüne yönelik bir bütünlesik karar destek modeli. 1999, İstanbul Teknik Üniversitesi: Fen Bilimleri Enstitüsü.

5. Tuncer, S.A. and A. Alkan, A decision support system for detection of the renal cell cancer in the kidney. Measurement, 2018. 123: p. 298-303.

6. Buffat, R., et al., GIS-based Decision Support System for Building Retrofit. Cisbat 2017 International Conference Future Buildings \& Districts - Energy Efficiency from Nano to Urban Scale, 2017. 122: p. 403-408.

7. Navarro-Hellin, H., et al., A decision support system for managing irrigation in agriculture. Computers and Electronics in Agriculture, 2016. 124: p. 121-131.

8. Yatskiv, I. and E. Yurshevich, Data Actualization Using Regression Models in Decision Support System for Urban Transport Planning. Theory and Engineering of Complex Systems and Dependability, 2015. 365: p. 553-561.

9. Ocalir-Akunal, E.V., Decision Support Systems in Transport Planning. World Multidisciplinary Civil Engineering-Architecture-Urban Planning Symposium 2016, Wmcaus 2016, 2016. 161: p. 1119-1126.

10. Naderi, S. and K. Kilic, A decision support system for staff workload balancing. 12th International Conference on Application of Fuzzy Systems and Soft Computing, Icafs 2016, 2016. 102: p. 6773.

11. Chi, H., et al., A decision support system for detecting serial crimes. Knowledge-Based Systems, 2017. 123: p. 88-101.

12. Hakli, H., H. Uguz, and T. Cay, A new approach for automating land partitioning using binary search and Delaunay triangulation. Computers and Electronics in Agriculture, 2016. 125: p. 129136.

13. Crossland, M.D., B.E. Wynne, and W.C. Perkins, Spatial Decision-Support Systems - an Overview of Technology and a Test of Efficacy. Decision Support Systems, 1995. 14(3): p. 219235.

14. Yomralıglu, T., Coğrafi bilgi sistemleri: Temel kavramlar ve uygulamalar. 2000, Seçil Ofset, İstanbul.

15. Jones, M. and G. Taylor, Data Integration Issues for a Farm Decision Support System. Transactions in GIS, 2004. 8(4): p. 459-477.

16. Pontius, R.G. and K. Si, Spatial Decision Support Systemsc. International Encyclopedia of the Social \& Behavioral Sciences (Second Edition), 2015: p. 136-141. 